\title{
Efficacy of 12 hourly controlled-release codeine compared with as required dosing of acetaminophen plus codeine in patients with chronic low back pain
}

\author{
Martin E Hale MD, Kevin L Speight MD, Zoltan Harsanyi MBA, Tad Iwan BA, N Susan Slagle MPH, \\ Peter G Lacouture PhD, Andrew C Darke PhD
}

ME Hale, KL Speight, Z Harsanyi, et al.

Efficacy of 12 hourly controlled-release codeine compared with as required dosing of acetaminophen plus codeine in patients with chronic low back pain.

Pain Res Manage 1997;2(1):33-38.

OBJECTIVE: To compare pain relief and stability of pain control in patients with chronic low back pain treated with scheduled 12 hourly doses of controlled-release codeine or as required doses of a fixed combination of acetaminophen and codeine.

PATIENTS AND METHODS: Patients were assigned to five days of treatment with controlled-release codeine (Codeine Contin; Purdue Frederick) $100 \mathrm{mg}$ q12h or placebo q12h in a randomized, double-blind, parallel group study. Acetaminophen $325 \mathrm{mg}$ $\mathrm{q} 4 \mathrm{~h}$ prn was available as rescue to the codeine group and acetaminophen $325 \mathrm{mg}$ plus codeine $30 \mathrm{mg}$ q $4 \mathrm{~h}$ prn was available to the placebo group. Pain intensity was assessed pretreatment and four times daily using a four-point categorical scale. Acceptability of therapy was assessed twice daily on a five-point scale.

RESULTS: Of 104 patients enrolled, 82 were able to be evaluated for safety and efficacy. Sum of pain intensity differences scores were significantly lower on controlled-release codeine than on as required acetaminophen plus codeine at all assessments. The number of changes in pain intensity throughout the day was higher with acetaminophen plus codeine than with codeine alone (8.6 0.7 versus 6.10 .6 , respectively, $\mathrm{P}=0.011)$. Mean total daily codeine dose was $200 \mathrm{mg}$ in the codeine group and $71.16 .6 \mathrm{mg}$ in the acetaminophen plus codeine group $(\mathrm{P}=0.0001)$. Mean total daily prn acetaminophen consumption was $542.286 .5 \mathrm{mg}$ in the codeine group and $770.871 .5 \mathrm{mg}$ in the fixed combination group $(\mathrm{P}=0.0452)$.

CONCLUSION: Twelve hourly dosing of controlled-release codeine provides greater and more stable pain relief in patients with chronic low back pain than as required dosing of an acetaminophen plus codeine combination.

Key Words: Codeine, Controlled-release dosing, Low back pain

Efficacité d'une codéine à libération contrôlée administrée toutes les 12 heures comparée à une association d'acétaminophène et de codéine administrée au besoin chez des patients présentant une lombalgie chronique

OBJECTIF : Comparer le soulagement de la douleur et la stabilité du contrôle de la douleur chez des patients présentant une lombalgie chronique traités toutes les 12 heures avec une dose de codéine à libération contrôlée ou avec des doses au besoin d'une combinaison fixe d'acétaminophène et de codéine.

PATIENTS ET MÉTHODES : On a assigné les patients à un traitement de 5 jours avec de la codéine à libération contrôlée (Codéine Contin, Perdue Frederick) à raison de $100 \mathrm{mg}$ toutes les 12 heures ou à un

voir page suivante

Park Place Therapeutic Center, Plantation, Florida; Bowman Gray School of Medicine, Winston-Salem, North Carolina; Purdue Frederick, Pickering, Ontario; The Purdue Frederick Company, Norwalk, Connecticut

Correspondence and reprints: Dr Andrew C Darke, Purdue Frederick, 575 Granite Court, Pickering, Ontario L1W 3W8. Telephone 905-420-6400, fax 905-420-1075

Received for publication August 16, 1996. Accepted October 10, 1996 
placebo toutes les 12 heures dans une étude de groupes parallèles, à double insu et randomisée. De l'acétaminophène à raison de $325 \mathrm{mg}$ toutes les 4 heures au besoin était disponible pour le groupe de la codéine, et une association d'acétaminophène à $325 \mathrm{mg}$ et de codéine à $30 \mathrm{mg}$ toutes les 4 heures au besoin était disponible pour le groupe placebo. On a évalué l'intensité de la douleur avant le traitement puis, 4 fois par jour, en utilisant une échelle absolue de 4 points. L'acceptabilité de la thérapie a été mesurée deux fois par jour sur une échelle de 5 points.

RÉSULTATS : Des 104 patients participant à l'étude, 82 ont pu être évalués relativement à la sûreté et à l'efficacité de la thérapie. La somme des scores de la différence de l'intensité de la douleur étaient considérablement moins élevée pour la codéine à libération contrôlée que pour l'association d'acétaminophène et de codéine au besoin, à toutes les évaluations. Le nombre de variations de l'intensité de la douleur au cours d'une journée était plus élevé avec la combinaison d'acétaminophène et de codéine qu'avec la codéine seulement (respectivement 8,6 $\pm 0,7$ comparé à $6,1 \pm 0,6, \mathrm{P}=0,011$ ). La dose de codéine quotidienne totale

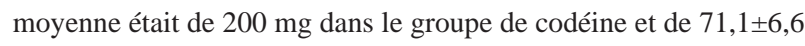
$\mathrm{mg}$ dans le groupe d'acétaminophène associé à de la codéine $(\mathrm{P}=0,0001)$. La consommation quotidienne totale moyenne d'acétaminophène au besoin était de $542,2 \pm 86,5 \mathrm{mg}$ dans le groupe de codéine et de $770,8 \pm 71,5 \mathrm{mg}$ dans le groupe de la combinaison fixe $(\mathrm{P}=0,0452)$.

CONCLUSION : La codéine à libération contrôlée administrée toutes les douze heures procure un soulagement de la douleur plus grand et plus stable chez les patients souffrant d'une lombalgie chronique qu'une combinaison d'acétaminophène et de codéine administrée au besoin.
$\mathrm{T}$ he optimal approach to both pharmacological and nonpharmacological management of chronic low back pain is of considerable clinical importance given its incidence among individuals in their wage-earning years (1-5).

Although opioids in cancer pain are now well established, their use in the treatment of chronic nonmalignant pain is less well accepted. Questions remain concerning long term efficacy, toxicity and addiction, and the possibility of adverse regulatory sanctions against prescribers of opioids, as identified in an extensive review by Portenoy (6). Data from placebo controlled clinical trials are limited to one trial of controlled-release morphine (7) and one of controlled-release codeine (8). A number of published surveys and open-label clinical trials also support the safety and effectiveness of opioid analgesics in carefully selected patients with chronic nonmalignant pain (9-20) including pain of neuropathic origin $(9,12,17$, $18,20-24)$. In response to this growing body of information several medical regulatory bodies, such as the College of Physicians and Surgeons of Alberta, have published guidelines on the appropriate use of opioids, including morphine, in chronic nonmalignant pain (25).

As in the treatment of cancer pain, current recommendations for opioid use in chronic nonmalignant pain are for scheduled dosing rather than as required administration $(17,20)$. However, with the exception of morphine - and more recently hydromorphone and oxycodone, which are available in controlled-release formulations to treat severe pain - most opioids require administration every $4 \mathrm{~h}$ to provide stable analgesia in patients with chronic pain.

The recent development of a controlled-release formulation of codeine (Codeine Contin; Purdue Frederick) has provided the opportunity to assess the benefits of 12 hourly dosing of an opioid in patients with less severe pain. A dose-response relationship for this single entity codeine formulation has been previously established in the range of 200 to $600 \mathrm{mg} /$ day in patients with cancer pain (26). The response to acetaminophen plus codeine $(600 / 60 \mathrm{mg}$ ) given four times a day in these patients was approximately equivalent to that of $150 \mathrm{mg}$ of controlled-release codeine given twice a day. At equianalgesic doses the adverse event profile of the two formulations was similar despite the higher dose of codeine provided by the single entity formulation. In a recent study of patients with chronic noncancer pain of varying etiologies (8) who received as required doses of an acetaminophen plus codeine combination, the addition of controlled-release codeine produced significant reductions in pain, rescue analgesic use and pain-related disability compared with placebo. It was therefore considered of interest to assess the efficacy and safety of controlled-release codeine compared with as required dosing of acetaminophen plus codeine in patients with chronic pain restricted to the lower back.

\section{PATIENTS AND METHODS}

Patients were recruited if they were assessed by the investigator at each centre to be in need of opioid or fixed combination codeine analgesics for the control of stable mild to moderately severe chronic low back pain. Male and female patients at least 18 years old were eligible for entry into the study provided there were no medical contraindications to their use of oral codeine or acetaminophen to manage pain.

\section{Study design}

A randomized, double-blind, parallel group design was used to compare a commonly used fixed combination preparation of acetaminophen plus codeine given as required, with a controlled-release codeine preparation given every $12 \mathrm{~h}$. Patients were randomly assigned to five days of either active controlled-release codeine $\mathrm{q} 12 \mathrm{~h}$ or matching placebo q12h. For patients in the codeine group, rescue medication was available as acetaminophen $325 \mathrm{mg}$ prn up to a frequency of every $4 \mathrm{~h}$ and was provided when pain was deemed unacceptable by the patient. Patients in the alternate treatment group received acetaminophen $325 \mathrm{mg}$ plus codeine $30 \mathrm{mg}$ fixed combination prn up to a frequency of every $4 \mathrm{~h}$.

To demonstrate an increase in low back pain on withdrawal of prior analgesics, patients were asked to discontinue all such medications for 24 to $96 \mathrm{~h}$ before entry into the study. Upon experiencing unacceptable low back pain within the 24 to $96 \mathrm{~h}$ period, patients returned to the investigator's office on day 0 (baseline) and were assigned to one of the treatments and given instructions for the use of their test medications. Dosing with controlled-release codeine $\mathrm{q} 12 \mathrm{~h}$ or placebo $\mathrm{q} 12 \mathrm{~h}$ commenced at 20:00. Consumption of rescue medication was allowed after the mid-day pain assessment.

Pain assessments were made before entry into the study (baseline = day 0 ) and then four times daily for five days during the double-blind period: morning (to assess overnight pain); mid-day 
(to assess morning pain); evening (to assess afternoon pain); and bedtime (to assess evening pain). Patients used a four-point scale to assess pain intensity $(0=$ no pain; $1=$ slight pain; $2=$ moderate pain; $3=$ severe pain). Acceptability of therapy, assessed twice daily, was based on consideration of both efficacy and side effects, and was rated by the patients using a five-point scale $(0=$ very poor; $1=$ poor; 2 = acceptable; 3 = good; 4 = excellent).

Adverse effects that occurred during the study were recorded and followed until resolution.

\section{Data analysis}

Average daily pain intensity scores were computed for each patient using the four ratings collected each day. Pain intensity differences (PID) were derived by subtracting each pain intensity score recorded during the study from the average of all ratings for a given patient on day 0 (baseline) (ie, before administration of the 12 hourly study medication). The sum of pain intensity difference (SPID) scores for each patient was calculated for each assessment time of day by summing the PID scores over each study day. Missing pain scores were infrequent; those that occurred were replaced with the patient's average score for the entire treatment period.

Multivariate repeated measures ANOVA was used to examine the effect of treatment, centre and study day on PID for each of the four daily assessment times, as well as for average daily pain intensity. The effect of centre was found to be not significant in every instance (lowest $\mathrm{P}$ value was 0.3478 ), and the analyses were therefore repeated without centre in the model. To examine the effect of time, a second repeated measures analysis that included time, day and treatment as independent factors was performed. SPID scores were compared by treatment separately for each of the four-daily assessment times and for the average of the daily assessments. Statistical significance was set at $\mathrm{P}=0.05$ for testing main effects and $\mathrm{P}=0.10$ for interactions, assuming a two-tailed hypothesis. All means are shown with corresponding SEs.

\section{RESULTS}

Of 104 patients enrolled in the study, 53 were randomized to controlled-release codeine and 51 to acetaminophen plus codeine. Eight-two patients were able to be evaluated for efficacy and safety, 38 in the codeine group (18 males, 20 females, mean age 53.22 .7 years) and 44 in the acetaminophen plus codeine group (19 males, 25 females, mean age 50.62 .3 years). Twenty patients (19\%) discontinued medication before completion of the study (15 on codeine and five on acetaminophen plus codeine). The most common reasons for discontinuation were adverse experiences $(n=13$ in the codeine group, $n=4$ in the fixed combination group), which were most frequently those typically associated with opioid use (dizziness, nausea, vomiting). One patient in the codeine group was lost to follow-up. Two patients, one from each treatment group, discontinued due to inadequate efficacy; however, they were considered able to be evaluated for efficacy.

The cause of low back pain was categorized as mechanical injury $(57 \%)$, arthritis (35\%) and other $(20 \%)$, with some patients reporting more than one cause. There was no difference between treatment groups with respect to cause of low back pain. The demographic characteristics of patients who were able to be evaluated for efficacy and safety are given in Table 1 .

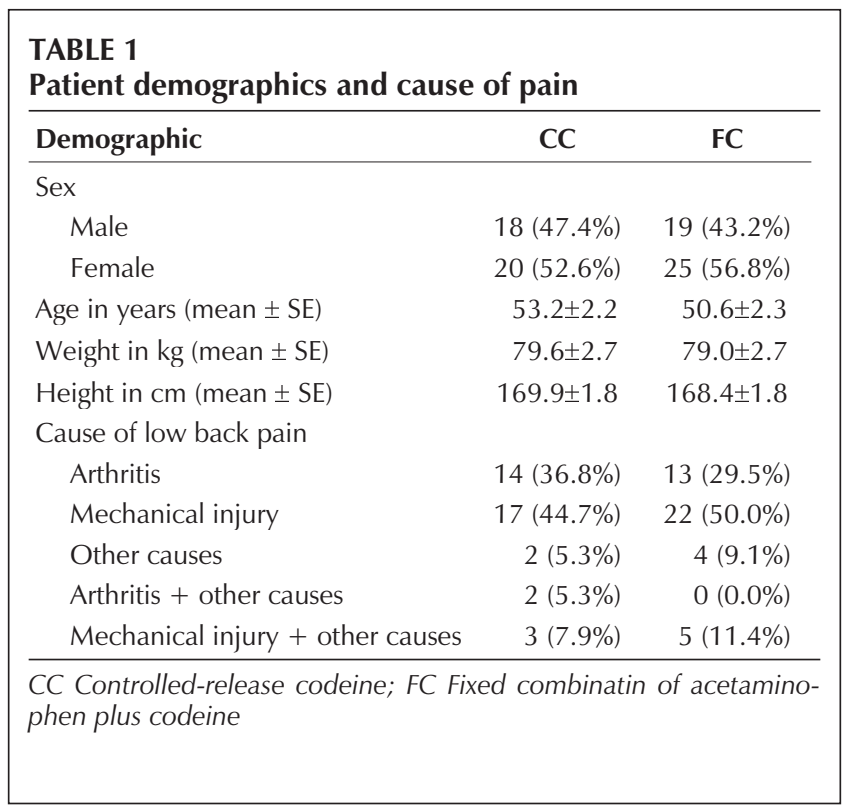

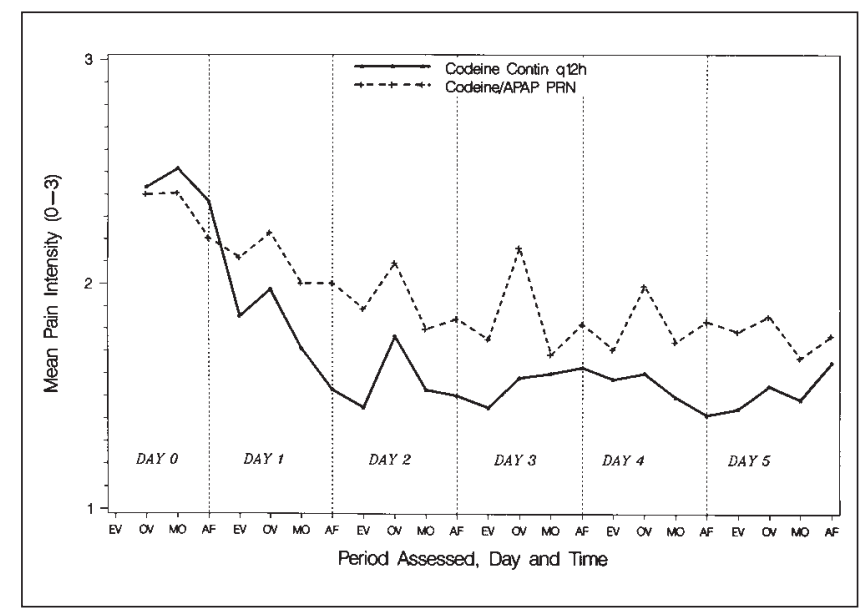

Figure 1) Mean pain intensity scores by time and day. AF Afternoon; APAP Acetaminophen; EV Evening; MO Morning; OV Overnight

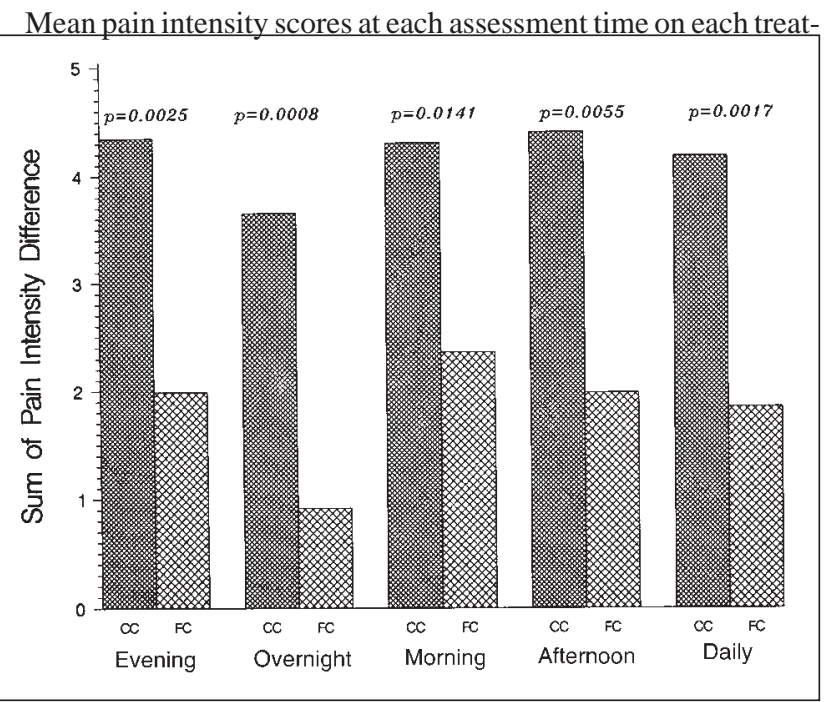

Figure 2) Mean sum of pain intensity differences. CC Controlled-release codeine group; FC Fixed combination of acetaminophen and codeine group 


\begin{tabular}{|c|c|c|}
\hline \multicolumn{3}{|c|}{$\begin{array}{l}\text { TABLE } 2 \\
\text { Fluctuations in pain intensity ratings over the five-day } \\
\text { study period }\end{array}$} \\
\hline & $\mathrm{CC}(\mathrm{q} 12 \mathrm{~h})$ & FC (prn) \\
\hline & Number of patients (\%) & Number of patients (\%) \\
\hline \multicolumn{3}{|c|}{ Increases in pain } \\
\hline None & $4(10)$ & $3(6.8)$ \\
\hline $1-3$ & $20(53)$ & $15(34)$ \\
\hline $4-6$ & $14(37)$ & $23(52)$ \\
\hline $7-9$ & $0(0)$ & $3(6.8)$ \\
\hline Mean & $2.95 \pm 0.30$ & $4.00 \pm 0.33$ \\
\hline \multicolumn{3}{|c|}{ Decreases in pain } \\
\hline None & $1(2.6)$ & $2(4.5)$ \\
\hline $1-3$ & $22(59)$ & $12(30)$ \\
\hline $4-6$ & $14(37)$ & $21(48)$ \\
\hline $7-9$ & $1(2.6)$ & $8(18)$ \\
\hline Mean & $3.16 \pm 0.29$ & $4.55 \pm 0.34$ \\
\hline \multicolumn{3}{|c|}{ Total number of fluctuations } \\
\hline None & $1(2.6)$ & $1(23)$ \\
\hline $1-3$ & $10(26)$ & $5(11)$ \\
\hline $4-6$ & $9(24)$ & $9(20)$ \\
\hline $7-9$ & $8(21)$ & $7(16)$ \\
\hline$\geq 10$ & $10(26)$ & $22(50)$ \\
\hline Mean & $6.11 \pm 0.57$ & $8.55 \pm 0.65$ \\
\hline
\end{tabular}

CC Controlled-release codeine; FC Fixed combinatin of acetaminophen plus codeine

ment day are presented in Figure 1. Pain scores decreased from baseline to day 1 on both treatments. However, they were lower in the codeine group than in the acetaminophen plus codeine group throughout the study, even though baseline scores were somewhat higher initially for the codeine group (2.42 0.11 versus 2.250 .09 , $\mathrm{P}=0.2184$ ). Mean SPID scores were statistically significantly higher in patients on codeine for each assessment (evening, overnight, morning, afternoon and daily average) (Figure 2). PID scores, analyzed using repeated measures ANOVA, differed significantly by day for all assessment times except afternoon, and none of the day by treatment interactions were significant. Pain scores varied by time of day $(\mathrm{P}=0.0094)$ but no significant treatment by time interaction was detected $(\mathrm{P}=0.4775)$. An intent to treat analysis based on 97 patients for whom at least some of the pain assessments were available ( $n=47$ in the codeine group, $n=50$ in the fixed combination group) was conducted. Results again showed that mean SPID scores were statistically significantly higher for those on codeine $(\mathrm{P}<0.02$ at all assessment times).

Variation in pain scores appeared greater in the fixed combination group, especially overnight, as shown in Figure 1. To quantify this apparent difference in pain intensity fluctuation the total number of increases, decreases and changes in pain intensity ratings were calculated for each patient across all study days (Table 2). The number of such fluctuations in pain intensity was significantly lower in those on codeine versus acetaminophen plus codeine (increases: 3.00 .3 versus $4.0 \quad 0.3$, respectively, $\mathrm{P}=0.032$; decreases: 3.20 .3 versus 4.60 .3 , respectively, $\mathrm{P}=0.006$ ). The magnitude of pain fluctuations (maximum to minimum) was not statistically different between treatments.

Use of as required analgesic was less in the codeine group than in the fixed combination group both overnight $(0.670 .12$ versus 0.860 .10 doses, respectively, $\mathrm{P}=$ not significant) and during the day ( 1.00 .16 versus 1.53 doses 0.15 , respectively, $\mathrm{P}=0.0183$ ). The mean daily dose of codeine was $200 \mathrm{mg}$ in the codeine group and $71.1 \mathrm{mg} 6.6$ in the acetaminophen plus codeine group $(\mathrm{P}=0.0001)$. Mean daily consumption of as required acetaminophen was significantly lower $(\mathrm{P}=0.0452)$ in the codeine group $(542.2 \mathrm{mg} 86.5$ versus $770.8 \mathrm{mg} 71.5)$.

Analysis of adverse event data was based on all patients who were able to be evaluated for safety ( $n=52$ in the codeine group, $\mathrm{n}=51$ in the fixed combination group) and therefore included patients who discontinued early due to side effects. The most frequently reported (greater than $5 \%$ of patients on either treatment) adverse events were those typical of opioid analgesics, ie, nausea, constipation, headache, dizziness, dry mouth, somnolence, vomiting, dyspepsia and pruritus (Table 3). In all cases except constipation, the number of reports was greatest in the codeine group, consistent with the higher dose of codeine received by these patients. Most of the side effects were of mild or moderate severity. Nausea, vomiting or both were reported as severe by eight patients

TABLE 3

Most frequent adverse events by number of patients and number of reports

\begin{tabular}{|c|c|c|c|c|c|c|c|c|}
\hline & \multicolumn{4}{|c|}{ Controlled-release codeine } & \multicolumn{4}{|c|}{ Acetaminophen plus codeine } \\
\hline & \# of pts & \# of reports & $\%$ of pts & $\%$ pts with SAE & \# of pts & \# of reports & $\%$ of pts & $\%$ pts with SAE \\
\hline Headache & 8 & 11 & 15.4 & 0 & 4 & 4 & 7.8 & 3.9 \\
\hline Dizziness & 9 & 11 & 17.3 & 3.8 & 2 & 2 & 3.9 & 0 \\
\hline Somnolence & 5 & 5 & 9.6 & 0 & 2 & 2 & 3.9 & 0 \\
\hline Nausea & 16 & 20 & 30.8 & 15.4 & 9 & 14 & 17.6 & 3.9 \\
\hline Vomiting & 5 & 5 & 9.6 & 7.7 & 1 & 1 & 2.0 & 2.0 \\
\hline Dyspepsia & 4 & 4 & 7.7 & 3.9 & 2 & 2 & 3.9 & 2.0 \\
\hline Constipation & 10 & 11 & 19.2 & 1.9 & 8 & 11 & 15.7 & 0 \\
\hline Dry mouth & 8 & 8 & 15.4 & 0 & 0 & 0 & 0 & 0 \\
\hline Pruritus & 3 & 5 & 5.8 & 3.8 & 2 & 2 & 3.9 & 2.0 \\
\hline
\end{tabular}

Pts Patients; SAE Severe adverse events 
$(15.4 \%)$ on codeine and three patients $(5.9 \%)$ on the fixed combination.

Controlled-release codeine $\mathrm{q} 12 \mathrm{~h}$ was rated as more acceptable than acetaminophen plus codeine both for overnight (1.97 0.16 versus 1.610 .13 , respectively, $\mathrm{P}=0.1325)$ and daytime (2.12 0.17 versus 1.840 .13 , respectively, $\mathrm{P}=0.3201$ ), but in neither case was this difference statistically significant.

\section{DISCUSSION}

Back pain represents the second most frequent symptomatic reason for physician office visits (27) and has an annual incidence of 5\% of the adult population (28). The escalating rate of disability due to chronic low back pain, reported in many countries, has led to reevaluation of a number of current treatment paradigms, as summarized in the recent report of the International Association for the Study of Pain (IASP) Task Force on Pain in the Workplace (29). Among the issues considered are the advantages of time-contingent treatment - in contrast to treatment that is linked to pain or painrelated behaviour - and, more generally, the relative roles of nonmedical and medical interventions, including the appropriate use of opioid analgesics.

Although the benefit of time-contingent dosing of analgesics is well accepted in the clinical management of cancer pain, experimental support for this approach is limited. In a recent study of cancer patients receiving as required doses of acetaminophen plus codeine, addition of 12 hourly doses of controlled-release codeine resulted in reduction of pain and a high degree of patient preference compared with placebo (30). Similar results were reported in patients with chronic nonmalignant pain (8), suggesting that optimal pain control in both groups of patients is limited by a patient's willingness to titrate medication adequately. Although the doses of controlled-release codeine in that study (mean dosage $273 \mathrm{mg} /$ day) were higher than the doses in this study of patients with low back pain $(200 \mathrm{mg} / \mathrm{day})$, the results are consistent in confirming improved pain control with time-contingent dosing compared with as required dosing of a short-acting analgesic. Application of a timecontingent approach to treatment of chronic low back pain has also been advocated because it removes the focus of treatment from the patient's pain or pain-related behaviours. This avoids the potentially adverse conditioning consequences inherent in an as required dosing strategy and facilitates efforts to make reduction of disability the goal of multidisciplinary therapy (29).

Our results also provide important additional information in the controversy surrounding opioids use in patients with chronic nonmalignant pain. A recent review (31) of the largely anecdotal evidence concluded that there is an adequate rationale for chronic use of opioids in carefully selected patients who have not responded adequately to other therapy. The present study, together with a number of other recent controlled trials of controlled-release mor-

\section{REFERENCES}

1. Rowe ML. Low back pain in industry: a position paper. J Occup Med 1969;11:161-9.

2. Kelsey JL, White AA, Pastides H, Bisbee GE. The impact of musculoskeletal disorders on the population of the United States. J Bone Joint Surg 1979;61:959-64.

3. Steinberg GG. Epidemiology of low back pain. In: Stanton-Hicks M, Boas R, eds. Chronic Low Back Pain. New York: Raven, 1982:1-13.

4. Anderson GPJ, Pope MH, Frymoyer JW. Epidemiology. In: Pope MH, Frymoyer JW, Anderson GBJ, eds. Occupational Low Back Pain. New York: Praeger, 1984:101-14.

5. United States Department of Health and Human Services, Social

PAIN RES MANAGE VOL 2 NO 1 SPRING 1997 phine (7), codeine (8) or oxycodone (32), supports these anecdotal observations with a consistent conclusion of analgesic effectiveness over treatment periods ranging from five days to nine weeks. Recent re-evaluation of existing treatment paradigms for chronic low back pain has resulted in considerable scepticism concerning the contribution of medical approaches, including analgesics, to the attainment of therapeutic goals such as reduction of disability and return to work (29). Although there are undeniable psychosocial dimensions to the disability associated with chronic low back pain, there is a risk that overemphasis on nonmedical approaches will deny patients the benefits of significant pain relief demonstrated with a controlled-release opioid preparation in this study. Additional studies should define the patient characteristics and history that most effectively predict both analgesic and functional benefits of opioids during long term treatment in patients with uncontrolled pain of nonmalignant origin.

An important but sometimes neglected feature of analgesic effectiveness determination is the measurement of fluctuation in pain. In this study not only were average pain scores significantly lower in the controlled-release codeine group, but also the number of increases or decreases in pain scores throughout the day was less with 12 hourly dosing of codeine than with as required administration of acetaminophen plus codeine, even though the magnitude of the fluctuations in pain did not differ between the two treatments. A similar reduction in fluctuations in other pharmacodynamic variables, such as mood, has been observed in normal volunteers treated with controlled-release codeine versus immediate-release codeine (33).

The relationship between reduced dosing frequency and improved compliance has been established in a wide range of therapeutic areas (34). Improved control of cancer pain with controlledrelease analgesic formulations has been associated with improved compliance compared with administration of short acting analgesics (35). Improved compliance and the longer duration of action of controlled-release preparations are therefore likely to be contributing factors to the more stable pain control achieved in this study with 12 hourly dosing of controlled-release codeine compared with as required dosing of the fixed combination preparation.

\section{CONCLUSIONS}

Around the clock 12 hourly dosing with controlled-release codeine provides greater and more stable pain relief than as required dosing of a short acting, fixed combination analgesic preparation. Timecontingent dosing of controlled-release opioid preparations is an effective strategy for relief of chronic low back pain and represents an important component of multidisciplinary therapy directed at reduction of disability.

Security Administration, Disability Survey, SSA Publication No. 13-11812, 1980.

6. Portenoy RK. Opioid therapy for chronic nonmalignant pain: current status. In: Fields HL, Liebesking JC, eds. Progress in Pain Research and Management. Seattle: IASP Press, 1994.

7. Moulin DE, Iezzi A, Amireh R, Sharpe WKJ, Boyd D, Merskey H. A randomized trial of oral morphine for chronic non-malignant pain. Lancet 1996;347:143-7.

8. Arkinstall W, Sandler A, Goughnour B, Babul N, Harsanyi Z, Darke AC. Efficacy of controlled-release codeine in chronic non-malignant pain: a randomized, placebo-controlled clinical trial. Pain 1995;62:196-78. 
9. Taub A. Opioid analgesics in the treatment of chronic intractable pain of non-neoplastic origin. In: Kitahata LM, Colins D, eds. Narcotic Analgesics in Anesthesiology. Baltimore: Williams and Wilkins, 1982:199-208.

10. Tennant FS, Uelmen GF. Narcotic maintenance for chronic pain: medical and legal guidelines. Postgrad Med J 1983;73:81-94.

11. France RD, Urban BJ, Keefe FJ. Long term use of narcotic analgesics in chronic pain. Soc Sci Med 1984;19:1379-82.

12. Portenoy RK, Foley KM. Chronic use of opioid analgesics in non-malignant pain: report of 38 cases. Pain 1986;25:171-86.

13. Tennant FS, Robinson D, Sagherian AS, Seecof R. Chronic opioid treatment of intractable non-malignant pain. Pain Manage 1988;Jan/Feb:18-26.

14. Wan Lu C, Urban B, France RD. Long-term narcotic therapy in chronic pain. Canadian Pain Society/American Pain Society meeting, Toronto, 1988.

15. Knight KL. The use of opioids for chronic pain in non-malignant disease. In: Twycross RG, ed. The Edinburgh Symposium on Pain Control and Medical Education. Royal Society of Medicine Services Internationl Congress and Symposium. Series No. 149. Edinburgh: Royal Society of Medicine, 1989:201-4.

16. Portenoy RK. Opioid therapy. In: Tollison CD, Kriegel ML, eds. Interdisciplinary Rehabilitation of Low Back Pain. Baltimore: Williams and Wilkins, 1989:137-57.

17. Portenoy RK. Chronic opioid therapy in nonmalignant pain. J Pain Symptom Manage 1990;5:S46-62.

18. Kanner R, Duarte R. Controlled-release morphine (CRM) in the treatment of pain of non- malignant origin. American Pain Society meeting, New Orleans, 1991.

19. Moran C. MST continus tablets and pain control in severe rheumatoid arthritis. Br J Clin Res 1991;2:1-12.

20. Zenz M, Strumpf M, Tryba M. Long-term opioid therapy in patients with chronic non-malignant pain. J Pain Symptom Manage 1992;7:69-77.

21. Urban BJ, France RD, Steinberger EK, Scott DL, Maltbie AA. Long-term use of narcotic/antidepressant medication in the management of phantom limb pain. Pain 1986;24:191-6.

22. Rowbotham M, Reisner-Keller LA, Fields HL. Both intravenous lidocaine and morphine reduce pain of post herpetic neuraligia. Neurology 1991;41:1024-8.

23. Pappagallo M, Campbell JN. Chronic opioid therapy as alternative treatment for post-herpetic neuralgia. Ann Neurol 1994;35:S54-6.
24. Watson CPN. Medical treatment of postherpetic neuralgia. In: Watson CPN, ed. Herpes Zoster and Postherpetic Neuralgia, 1st edn. New York: Elsevier, 1993:205-19.

25. Hagen N, Flynne P, Hays H, MacDonald N. Guidelines for managing chronic non-malignant pain. Can Fam Physician 1995;46:49-53.

26. Chary S, Goughnour BR, Moulin DE, Thorpe WR, Harsanyi Z, Darke AC. The dose-response relationship of controlled-release codeine (Codeine Contin) in chronic cancer pain. J Pain Symptom Manage 1994;9:363-71.

27. Lemrow N, Adams D, Coffey R et al. The 50 Most Frequently Diagnosis-related Groups (DRG's), Diagnoses, and Procedures: Statistics by Hospital Size and Location. DHHS Publication no. (PHS) 90-3465, Hospital Studies Program Research Note 13. Rockville: Agency for Health Care Policy and Research, 1990.

28. Frymoyer J, Cats-Baril W. An overview of the incidences and costs of low back pain. Orthop Clin North Am 1991;22:263-71.

29. Fordyce WE, ed. Back Pain in the Workplace. Management of Disability in Nonspecific Conditions. A Report of the Task Force on Pain in the Workplace of the International Association for the Study of Pain. Seattle: IASP Press, 1995.

30. Dhaliwal H, Sloan P, Arkinstall W, et al. Randomized evaluation of controlled-release codeine and placebo in cancer patients. J Pain Symptom Manage 1995;10:612-23.

31. Schug SA, Large RG. Opioids for chronic non-cancer pain. Pain Clinical Updates 1995;3:1-4.

32. Roth S, Burch F, Fleischmann R, et al. The effect of controlled-release (CR) oxycodone on pain intensity and activities in patients with pain secondary to osteoarthritis. American Pain Society 14th Annual Meeting Program Book. Glenview: American Pain Society, 1995:A147. (Abst \#95884)

33. Lacouture PG, Fitzmartin RD, Kaiko RF, Grandy RP, Goldenheim PG The modifying effect of controlled-release (CR) vs immediate release (IR) opiate on mood. College on Problems of Drug Dependence, Palm Beach, 1994.

34. Sbarbaro JA. Strategies to improve compliance with therapy. Am J Med 1985;79(Suppl 6A):34-7.

35. Ferrell B, Wisdom C, Wenzl C, Brown J. Effects of controlled-release morphine on quality of life for cancer pain. Oncol Nurs Forum 1989;16:521-6. 


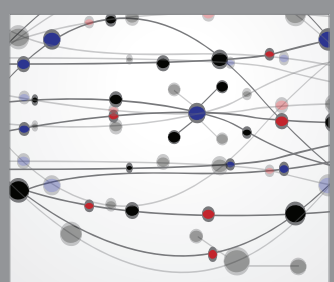

The Scientific World Journal
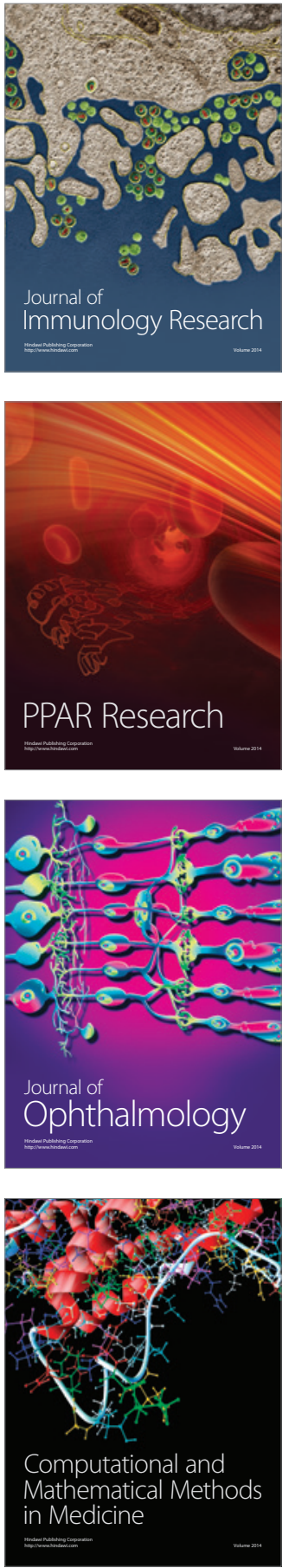

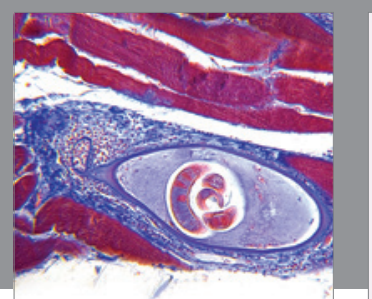

Gastroenterology Research and Practice

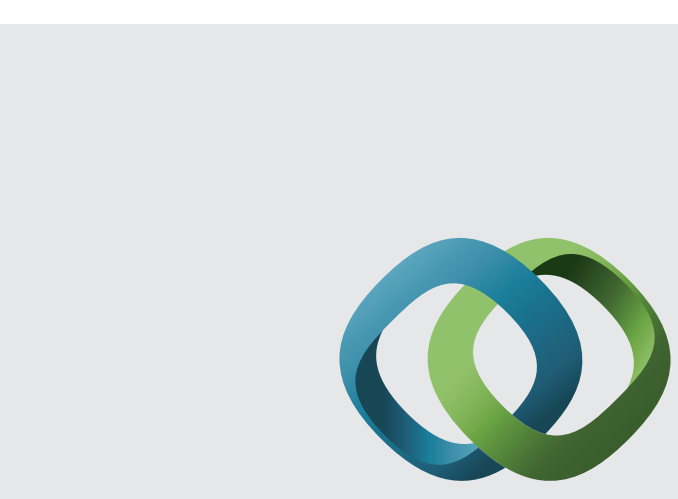

\section{Hindawi}

Submit your manuscripts at

http://www.hindawi.com
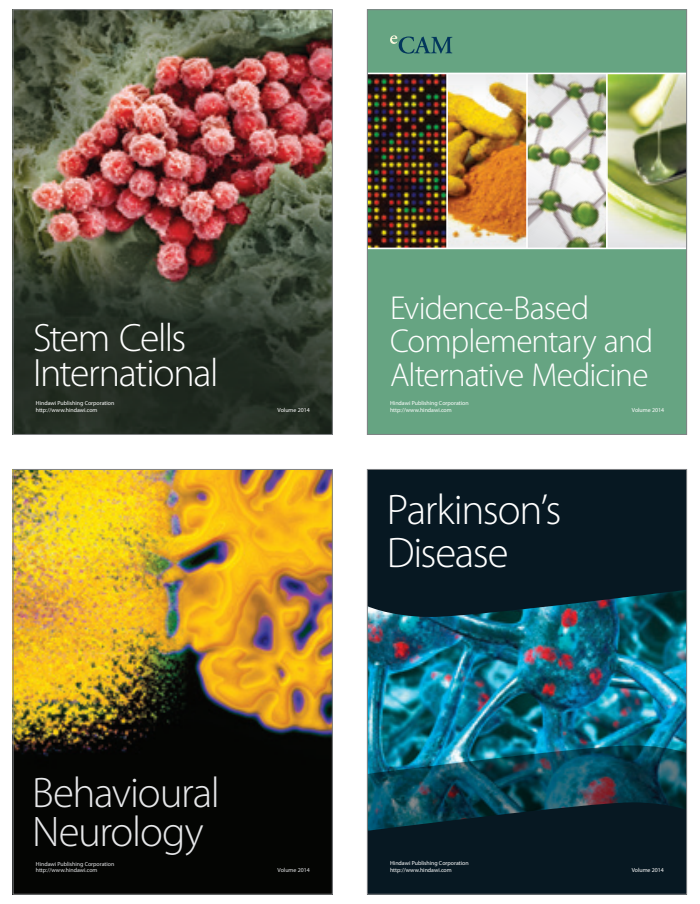
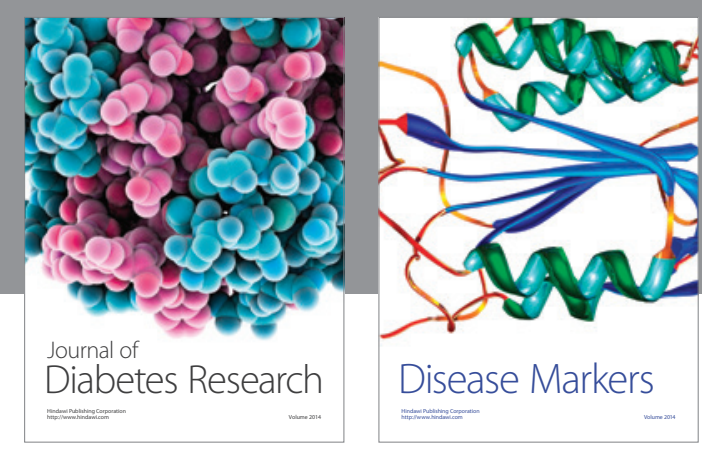

Disease Markers
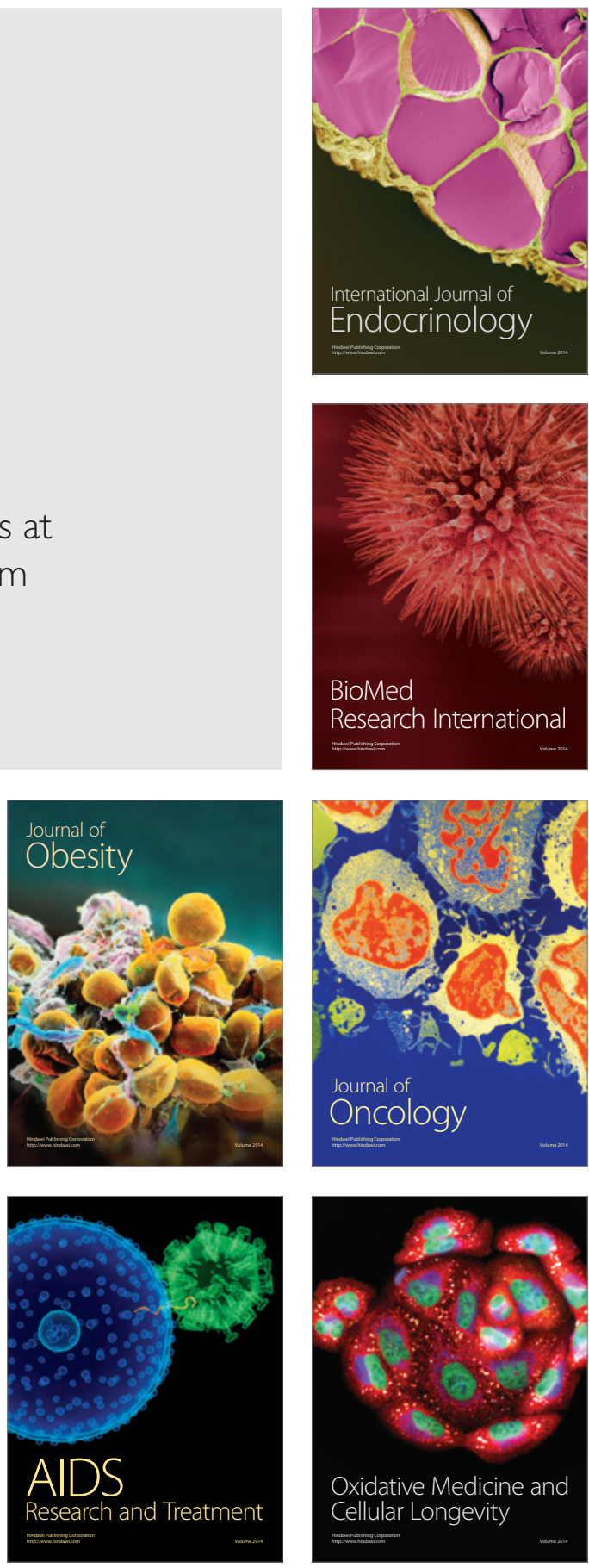